\title{
EXTRAÇÃO DE PROFUNDIDADES MEDIANTE REDES NEURAIS ARTIFICIAS E MODELO DE REGRESSÃO USANDO DADOS DE LEVANTAMENTO GPS E DE IMAGEM IKONOSII - ESTUDO COMPARATIVO
}

\author{
Selma Regina Aranha Ribeiro ${ }^{1}$ \\ Andréa Tedesco ${ }^{2}$ \\ Cláudia Pereira Krueger ${ }^{1}$ \\ Jorge Antonio Silva Centeno ${ }^{1}$
}

\begin{abstract}
Resumo: O presente trabalho propõe uma comparação entre duas metodologias, a de redes neurais artificiais (RNA) e o modelo de regressão (MR), para estimar profundidades batimétricas a partir de imagens IKONOS II. Como variáveis foram adotados os valores do contador digital de duas bandas espectrais do sistema IKONOS II e a posição do pixel, dada pelas coordenadas (E, N). A primeira metodologia consiste de uma regressão linear (RL) e a segunda em uma RNA de duas camadas escondidas, do tipo feed forward. O estudo comprova que as metodologias geram resultados que atendem as especificações técnicas da Diretoria de Hidrologia e Navegação (DHN), responsável pelas publicações náuticas no Brasil, para levantamentos batimétricos (LB) de Ordem 1 , sendo o erro máximo permitido, para esta ordem, entre 0,25 a $0,50 \mathrm{~m}$. No entanto, verificou-se que ambas atendem uma faixa restrita de profundidade, entre $0,80 \mathrm{~m}$ a $3,00 \mathrm{~m}$, nos quais a resposta espectral da coluna de água prevalece sobre o reflexo do fundo e não é fortemente afetada pela absorção.
\end{abstract}

Palavras-Chave: Sensoriamento remoto, Imagens de alta resolução, NAVSTAR-GPS,Batimetria.

\begin{abstract}
In this article, we describe the comparison between two methodology, artificial neural network (ANN) and regression model (RM) for the estimate of bathymetry using satellite imagery (IKONOS II). The input variables of the model are the digital values of two spectral bands and the position of the pixel, given by its N, E coordinates were adopted. The first methodology consists in a linear regression and the second a ANN of the two hidden layers, The proposed model consists of an artificial feed forward neural net with two hidden layers like feed forward. The study reveals that the two methodologies are able to produce results that satisfy technical specifications of Diretoria de Hidrologia e Navegação (DHN), responsible for the bathymetric surveys in Brazil, for class 1 surveys, because the maximum error lies bellow $0,5 \mathrm{~m}$. However, it was also verified that the methodologies are efficient only for restricted depths, among 0,80 to 3,00 m, where the spectral response of the water column water prevails on the spectral response of the bottom and it is not strongly affected by absorption.
\end{abstract}

Keywords: Remote Sensing, High resolution images, NAVSTAR-GPS, bathymetry.

\footnotetext{
${ }^{1}$ Depto. de Geomática, Universidade Federal do Paraná - (Selma, CKrueger, Centeno@ufpr.br).

${ }^{2}$ Depto. de Engenharia, Universidade Estadual do Oeste do Paraná - (tedescodeda@unioeste.br).
} 


\section{INTRODUÇÃO}

O Brasil é um país de grandes extensões, possui imenso litoral e grande quantidade de rios navegáveis, que são utilizados para o lazer, transporte de pessoas e cargas. A necessidade de se manter uma cartografia náutica atualizada e confiável é uma necessidade para os usuários destes recursos, pois devido aos processos naturais de erosão e deposição em rios e em áreas costeiras, ocorrem alterações significativas no fundo, como a formação de bancos de areias e lodos.

A execução e controle dos levantamentos hidrográficos, bem como a produção e edição das cartas náuticas, são atribuições da Marinha do Brasil, por meio da DHN. Para a execução destes levantamentos são necessárias medições precisas de profundidade usando equipamentos como ecobatímetros a bordo de barcos, mas tais métodos resultam caros e demorados, motivo este que justifica a busca de alternativas menos onerosas. A aplicação de SR passivo, em função de sua visão panorâmica de uma região, é uma opção pertinente, principalmente na atualidade, com o aumento da resolução espacial das imagens comercialmente disponíveis.

Este estudo visa mediante dados de posição (N, E) e de SR a utilização de duas metodologias, o MR e a RNA, para a obtenção de profundidades no litoral paranaense, mais precisamente em um canal situado entre as ilhas Sepultura e do Capinzal, na baía de Guaratuba.

\section{REVISÃO DE LITERATURA}

\subsection{LEVANTAMENTOS HIDROGRÁFICOS}

Dentre os principais propósitos, os Levantamentos Hidrográficos (LH) destinam-se à confecção ou atualização de cartas e publicações náuticas. Eles são realizados exclusivamente pela DHN, através do Centro de Hidrografia da
Marinha (CHM). Os LH podem ser executados por entidades nacionais extraMarinhas, e são regulamentados pelo art. 37 do Decreto-lei 243 de 28 de fevereiro de 1967, o qual foi regulamentado pela Portaria Ministerial 53/MB de 01 de março de 2002 (BRASIL, 2002).

As cartas náuticas são documentos cartográficos que resultam de levantamentos de áreas oceânicas, mares, baías, rios, canais, lagos, lagoas, ou qualquer outro corpo de água navegável, e se destinam a servir de base à navegação. Representam os acidentes terrestres e submarinos, fornecendo informações sobre profundidades, perigos à navegação (bancos, pedras submersas, cascos soçobrados ou qualquer outro obstáculo à navegação), natureza do fundo, fundeadouros e áreas de fundeio, auxílios à navegação (faróis, faroletes, bóias, balizas, luzes de alinhamento, radiofaróis, etc.), altitudes e pontos notáveis aos navegantes, linha de costa e de contorno das ilhas, elementos de marés, correntes e magnetismo e outras indicações necessárias à segurança da navegação (MIGUENS, 2000).

De acordo com os diferentes requisitos de precisão, foram definidas quatro ordens de levantamento: Ordem Especial, Ordem 1, Ordem 2 e Ordem 3 (BRASIL, 2002). A ordem de levantamento descrita a seguir é a 1 e de interesse para este estudo.

Ordem 1: destinam-se às áreas portuárias, canais de acesso, rotas recomendadas, canais de navegação interior e áreas costeiras com grande densidade de tráfego mercante, onde a folga sob a quilha seja menos crítica e as propriedades geofísicas do fundo sejam menos perigosas à navegação (como fundo de lama ou arenoso). Os levantamentos desta ordem devem limitar-se às áreas com profundidades menores que 100 metros. Conforme as especificações mínimas para LH, preconizações pela DHN, as 
profundidades devem ter precisão entre $0,25 \mathrm{~m}$ e $0,50 \mathrm{~m}$ para Ordem 1 , e entre $0,50 \mathrm{~m}$ e $1,00 \mathrm{~m}$ para Ordens 2 e 3, para níveis de confiança de 95\% (DHN, 1998) .

\subsection{LEVANTAMENTO UTILIZANDO ECOBATÍMETRO}

A medição de profundidade pode ser realizada de forma direta ou indireta, no segundo caso aplica-se, por exemplo, sensores acústicos, ou seja, ecobatímetro de feixe único ou multifeixe.

$\mathrm{O}$ princípio fundamental de um ecobatímetro consiste em que um feixe de ondas sonoras ou ultra-sonoras seja transmitido verticalmente por um emissor instalado na embarcação, atravessando o meio líquido até atingir o fundo submerso, conseqüentemente refletindo-se e retornando à superfície, onde é detectado por um receptor. O tempo decorrido entre a emissão do sinal e a recepção do eco refletido do fundo submerso é convertido em profundidade, visto que a velocidade do som na água é conhecida. A Equação 1 mostra o cálculo da profundidade.

$\mathrm{p}=0,5 * \mathrm{~V} * \mathrm{t}$

Sendo:

$\mathrm{p}=$ profundidade;

$\mathrm{v}=$ velocidade de propagação do som na água, e

$\mathrm{t}=$ tempo gasto pelo sinal para ir ao fundo e retornar.

Este equipamento conta com um gravador gráfico de papel, que registra as profundidades em escala adequada, e que permite correções manuais em casos de dúvida sobre as profundidades registradas. Os dados podem ser visualizados também em forma digital para ecobatímetros que possuam o dispositivo adequado. Os dados podem ainda ser enviados em tempo real para um computador portátil acoplado ao ecobatímetro, utilizando um programa específico e armazenados para posterior processamento (TEDESCO, 2003).

ENGEVISTA, v. 7, n. 1, p. 73-82, abril 2005
Enquanto o ecobatímetro determina a profundidade é necessário também determinar a posição do ponto medido em termos planimétricos. Tradicionalmente, a posição pode ser medida utilizando teodolitos para marcar a trajetória da nave durante o levantamento, mas desde a última década o uso de sistemas de posicionamento por satélites, como NAVSTAR-GPS, é o método mais difundido.

A qualidade da informação a respeito da posição do ecobatímetro obtida com GPS depende do método utilizado. No posicionamento de embarcações, tanto o posicionamento absoluto como no relativo não satisfazem as necessidades. No posicionamento relativo tem-se a perda de sinal e é obrigatório o pós-processamento, já o absoluto não proporciona a acurácia necessária (SEEBER, 1993). Nestes casos, como no estudo presente, faz-se mister o uso do DGPS (Differential GPS). Ele consiste em utilizar simultaneamente dois receptores, um instalado em uma estação fixa de coordenadas conhecidas, denominada de estação de referência, e um outro em uma estação itinerante, em permanente movimento, intitulada de estação móvel. A partir da estação de referência são calculadas correções (correções diferenciais), as quais são utilizadas pela estação móvel no processo de cálculo de sua posição. As correções são enviadas em tempo real por meio de um sistema de comunicação e dentro de um formato apropriado, definido pela RTCM (Radio Technical Committee for Marine Service) (KRUEGER, 1996). Este método de posicionamento atende a acurácia horizontal com nível de confiança de 95\% de acordo com as especificações para levantamentos geográficos.

O resultado do uso conjunto do GPS e ecobatímetro, após sua transformação para o sistema de referência adotado, é um conjunto de dados tridimensionais de 
coordenadas de pontos na superfície do fundo.

\subsection{SENSORIAMENTO REMOTO E BATIMETRIA}

Uma alternativa para a estimativa da profundidade de corpos de água é o uso de imagens de SR. Neste caso, imagens da área em questão são obtidas utilizando sensores instalados em satélites. Os dados são coletados em faixas específicas do espectro eletromagnético, sendo que em algumas delas é possível registrar a energia refletida pelo fundo de corpos de água.

Por meio de imagens de satélite é possível estabelecer a relação entre a resposta espectral, medida sob forma de valores do contador digital, e a profundidade, para produzir cartas batimétricas com base em todos os pixels representativos de áreas submersas da imagem. No entanto, fatores como turbidez da água, características do fundo, ângulo de iluminação, materiais em suspensão, profundidade, entre outros, alteram a resposta espectral da água. Por isso, são necessários cuidados na interpretação dos dados (TEDESCO, 2003).

Quanto à transmitância, a água pura transmite muita radiação incidente nos comprimentos de onda inferiores a $0,6 \mu \mathrm{m}$. Este comportamento é semelhante ao dos oceanos e lagos limpos. A transmitância dos corpos d'água naturais diminui com o aumento da turbidez da água, enquanto que o comprimento de onda de máxima transmitância aumenta. A melhor região para as medidas espectrais da água é em torno de $0,48 \mu \mathrm{m}$, onde a transmitância é máxima (SWAIN \& DAVIS, 1978).

Métodos para a estimativa de profundidade que usam dados de SR foram propostos por autores como LYZENGA (1985), SPITZER e DIRKS (1987) e ABDULAH, MATJAFRI e DIN (2000). Estes autores realizaram estudos visando a atualização de mapas batimétricos a partir de imagens dos ENGEVISTA, v. 7, n. 1, p. 73-82, abril 2005 sensores Landsat TM e SPOT, usando dados obtidos em levantamentos batimétricos (LB) para estabelecer o modelo mais apropriado, baseado em análise de regressão. Os mapas gerados foram considerados satisfatórios, pois eram similares aos dados obtidos pelo LB, mas erros foram detectados, como por exemplo, aqueles causados pela interferência da turbidez da água.

As experiências utilizando imagens de média resolução espacial, como SPOT e Landsat TM, apontam a viabilidade do uso de SR na estimativa de profundidades. A aplicação de SR passivo, no entanto, é restringida a áreas de águas rasas e claras, com mudanças pequenas em tipos de fundo e em regiões livres de contaminação atmosférica (ABDUALLAH et al. 1991). Os recentes avanços em termos de novos sensores, com melhor resolução espacial e espectral, abriram espaço para a pesquisa de novos métodos, justificada pelo fato de que as regiões mais rasas, onde a estimativa usando imagens de média resolução espacial era viável não se encontra mais representada por uma estreita faixa de pixels, pois com o aumento da resolução espacial a região em questão é representada com maior detalhe. Por exemplo, a área coberta por um pixel do Landsat TM pode atualmente ser representada por 900 pixels, no caso do sistema IKONOS II.

O satélite IKONOS II está operacional desde o início de janeiro de 2000. É um satélite comercial capaz de coletar dados pancromáticos e multiespectrais com resolução espacial de $1 \mathrm{~m}$ e de $4 \mathrm{~m}$, respectivamente. Os dados de todas as bandas são armazenados em 11 bits (CENTENO, 2004). As bandas podem estar separadas, combinadas em um único arquivo ou mediante a técnica da fusão da imagem pancromática com a multiespectral. A desvantagem, na utilização da imagem fundida, é que no 
processo de fusão a imagem tem seus níveis digitais alterados.

Devido às deformações geométricas resultantes do imageamento por satélite, as imagens são previamente georeferenciadas e passam por um processo de reamostragem (interpolação) no qual os valores digitais são interpolados. Outra desvantagem, além da alteração dos valores digitais, devido aos processos de fusão e georeferenciamento, é que dificilmente as imagens são obtidas de um ângulo vertical (posição nadiral). No que diz respeito à determinação de profundidades em corpos d'água, isto implica que a resposta espectral da água, obtida pela observação da reflectância, corresponde a um feixe de incidência inclinado.

\subsection{REDES NEURAIS ARTIFICIAIS (RNA)}

As RNA são um ramo da inteligência artificial (IA) que se baseia no princípio de simular parte do funcionamento do cérebro humano usando computadores eletrônicos. Neste modelo, o considera-se que o cérebro é formado por neurônios interligados, compondo uma complexa rede, onde a informação flui sob forma de impulsos. Vários impulsos podem chegar simultaneamente a um neurônio através da rede. O neurônio processa, pondera e avalia estes impulsos no seu corpo, ou soma. Se intensidade dos impulsos recebidos, devidamente modulada, for suficientemente grande, o neurônio repassa um novo impulso a outros neurônios (Ribeiro, 2003).

Nas RNA, a idéia é simular o funcionamento de um neurônio usando equações matemáticas e compor uma rede de neurônios artificiais, na qual informações lógicas ou valores numéricos possam ser processados para gerar uma saída. No neurônio artificial; as entradas são valores numéricos $\left(\mathrm{x}_{1}, \mathrm{x}_{2}, \ldots, \mathrm{x}_{\mathrm{n}}\right)$, os quais são ponderados e somados para compor um único sinal de entrada, como mostrado na Equação 2.

$$
\mathrm{S}=\mathrm{b}+\Sigma \mathrm{x}_{\mathrm{i}} * \mathrm{~W}_{\mathrm{i}}
$$

Onde $\mathrm{b}$ é um valor constante próprio do neurônio, conhecido como "bias" e " $\mathrm{W}_{\mathrm{i}}$ " representa o fator de ponderação, isto é, o peso de cada entrada. A soma ponderada é então modulada usando uma função de transferência. Para tanto existem diferentes opções, como funções binomiais, lineares ou exponenciais.

As RNA são usualmente organizadas em camadas compostas de unidades de processamento (neurônios), conectadas por canais de comunicação que fazem fluir dados numéricos. Os dados são apresentados à rede por meio de uma camada de entrada, a qual se comunica a uma ou mais camadas ocultas (Figura 1) onde ocorre o processamento por meio de um sistema de conexões ponderadas. A camada de saída apresenta o resultado do processamento (GERMAN e GAHEGAN, 1996).

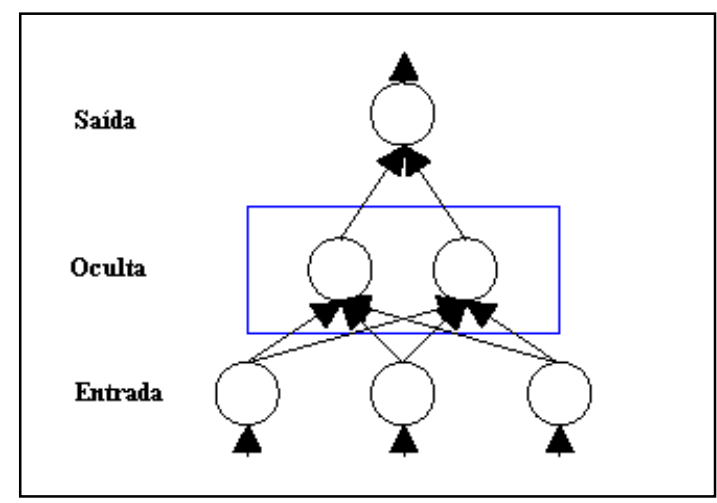

Figura $1-$ Modelo de uma RNA multicamada.

A chave do uso de uma RNA para a solução de um determinado problema consiste no ajuste de seus pesos, o que é feito numa primeira fase de treinamento. Treinar uma rede significa ajustar a sua matriz de pesos $\left(\mathrm{W}_{\mathrm{i}}\right)$ de forma que o vetor de saída coincida com certo valor desejado para cada vetor de entrada. Como o treinamento supervisionado necessita de 
pares de entrada e saída, esses são chamados de conjunto de treinamento. No treinamento, o vetor de entrada é aplicado e a saída da rede calculada. Comparando a resposta da rede com o vetor de saída esperado o erro é calculado. Com base neste erro, os pesos são ajustados a fim de minimizar essa diferença. $\mathrm{O}$ processo de treinamento é repetido até que, o erro para o conjunto de treinamento alcance um valor mínimo ou limite previamente determinado HAYKIN (1999).

$\mathrm{O}$ algoritmo para treinamento de RNA mais conhecido é o Backpropagation ou da retropropagação do erro. Ele utiliza o conceito de minimização do gradiente descendente e o limiar da função "sigmóide", considerado uma generalização da Regra Delta para RNA feed forward. A Regra Delta ou do erro quadrático mínimo utiliza um conjunto de treinamento com o qual se pretende uma aproximação linear, de tal forma que se obtenha a melhor aproximação possível no sentido do erro quadrático (GERMAN e GAHEGAN, 1996).

A RNA pode ser treinada para diferentes finalidades. No SR, as RNA têm comprovado utilidade para resolver problemas de classificação multiespectral, considerando dados de diferentes origens e escalas (RIBEIRO e CENTENO, 2002). Porém, seu uso não se restringe a este problema, sendo aplicável também na estimativa de modelos, como é descrito neste artigo.

\subsection{MODELO DE REGRESSÃO LINEAR}

$\mathrm{O}$ método de RL proposto neste estudo considera que, a partir de alguns dados de profundidade coletados em campo é possível estabelecer a relação entre a imagem de alta resolução espacial e radiométrica e a profundidade do corpo d'água, determinando-se facilmente os parâmetros de correlação entre as grandezas analisadas. O modelo proposto é dado pela Equação 3.

$\mathrm{Z}=\mathrm{a}_{0}+\mathrm{a}_{1} * \ln \mathrm{DN}$

Sendo:

$\mathrm{Z}=$ profundidade;

$\mathrm{a}_{0}$ e $\mathrm{a}_{1}=$ parâmetros de correlação entre profundidades e valores digitais, e

ln $\mathrm{DN}=$ logaritmo neperiano do valor digital do pixel (número digital) na banda considerada.

Por tratar-se de uma regressão linear (RL), os parâmetros "a $a_{0}$ " e "a 1 " são os coeficientes que definem a reta, sendo " $\mathrm{a}_{0}$ " o ponto de interceptação da reta no eixo "y" e "a" o coeficiente de inclinação da mesma. Para o cálculo dos parâmetros foram utilizados os valores das profundidades e dos logaritmos neperianos dos níveis digitais, para cada ponto considerado.

\section{MATERIAIS E MÉTODOS}

\section{1. ÁREA DE ESTUDO E MATERIAIS}

Mediante a Figura 2 pode-se localizar a área de estudo. As ilhas, Sepultura e do Capinzal, fazem parte do litoral paranaense na região sul do país, tendo nas proximidades as cidades de Matinhos, Caiobá e Guaratuba.

Uma imagem IKONOS II da região foi obtida em 16/09/2001. Este sistema possibilita obter imagens com resolução radiométrica de 11 bits. Suas bandas multiespectrais abrangem as faixas de Banda 1: 0,45 a 0,52 $(\mu \mathrm{m})$; Banda 2: 0,51 a 0,60 $(\mu \mathrm{m})$; Banda 3: 0,63 a 0,70 $(\mu \mathrm{m})$ e Banda 4: 0,76 a 0,85 $(\mu \mathrm{m})$, com resolução espacial de $4 \mathrm{~m}$ (nominal a $26^{\circ}$ nadir). A banda pancromática $(0,76-0,90 \mu \mathrm{m})$ tem resolução espacial de $1 \mathrm{~m}$. A imagem utilizada no estudo é o resultado da fusão das bandas multiespectrais (2, 3 e 4) com a banda pancromática. 


\subsection{MÉTODOS}

\section{RNA:}

Neste estudo, uma RNA foi proposta para obter um modelo que estimasse a profundidade a partir dos dados espectrais e das coordenadas planimétricas $(\mathrm{N}, \mathrm{E})$. Para isto, as variáveis de entrada foram inicialmente definidas. Elas são: a posição do pixel, dada pelas coordenadas planimétricas (N, E) e as leituras do contador digital (níveis digitais) em duas bandas espectrais a banda 2 (verde) e a 3 (vermelho) da imagem IKONOS II. Para obter um conjunto de treinamento confiável, foram escolhidos pontos onde, além das variáveis de entrada, a profundidade medida pelo ecobatímetro, era conhecida. Para isto, são selecionadas algumas linhas transversais do LB, executado no local de estudo, 12 perfis. A quantidade de amostras de treinamento coletadas é de 68 pontos, contendo os valores digitais das duas bandas espectrais e as coordenadas planimétricas, na faixa de 0,80 a $3,00 \mathrm{~m}$ de profundidade dos perfis levantados. Estas amostras são intercaladas para que o "aprendizado" da RNA não se torne tendencioso.

O segundo estágio é encontrar a melhor arquitetura da rede, ou seja, o número de camadas escondidas e número de neurônios por camada. A quantidade de neurônios da primeira camada é igual ao número de variáveis de entrada, no caso quatro (duas bandas espectrais da imagem IKONOS II e as coordenadas planimétricas, $\mathrm{N}$ e $\mathrm{E}$ ). $\mathrm{O}$ número de nós da camada de saída é definido em função da quantidade de variáveis de saída, neste caso apenas uma, a profundidade. As camadas escondidas, bem como o número de nós (neurônios) em cada camada escondida, são definidas experimentalmente, ou seja, em função da complexidade do problema. Testes foram realizados variando a arquitetura sendo que os melhores resultados foram obtidos utilizando duas camadas escondidas com 9 e 3 neurônios na primeira e segunda camada escondidas, respectivamente. Esta arquitetura concorda com o resultado de experimentos realizados por GERMAN e GAHEGAN (1996), os que afirmam que o número de nós da segunda camada escondida deve ser um terço da quantidade de nós da primeira camada escondida.

Após a definição das variáveis de entrada, da escolha das amostras de treinamento e da arquitetura da rede fixada, a RNA é treinada pelo método supervisionado utilizando o método de aprendizado Backpropagation e a variação RPROP (Resilient), presentes no tools box neural network do Laboratório Matemático Matlab 5.3. Durante o treinamento definiuse como critério para o processo de aprendizado o erro máximo limitado em $0,25 \mathrm{~m}$ (erro médio quadrático).

Uma vez treinada, a RNA pode ser usada para simular profundidades em função de um vetor de entrada contendo as leituras digitais das imagens e a posição planimétrica do local. Com o objetivo de verificar a capacidade da RNA de simular corretamente profundidades para pontos diferentes dos usados no treinamento, um novo conjunto, de verificação, composto por quatro linhas do LB, foi selecionado. Estes dados foram utilizados para a verificação e fornecem o erro cometido, ou seja, a diferença entre as profundidades fornecidas pela RNA e as lidas no ecobatímetro quando do levantamento.

A estimativa da profundidade usando imagens digitais oriundas de SR não é eficiente em regiões muito rasas, onde a resposta espectral do fundo predomina, nem em locais muito profundos, onde o feixe incidente é absorvido e não ocorre reflexão. Para avaliar a faixa de profundidade na qual os resultados são coerentes, o experimento foi repetido para diferentes faixas. Destes experimentos concluiu-se que a faixa de profundidade mais apropriada é entre 0,80 a $3,00 \mathrm{~m}$. 


\section{MR:}

Utilizando-se o programa Microsoft Excel, calcularam-se os parâmetros " $\mathrm{a}_{0}$ " e " $\mathrm{a}_{1}$ ", para todo o conjunto de dados (dos 12 perfis selecionados para os cálculos de RL) e também para intervalos distintos de profundidades. Estes intervalos foram definidos de modo que abrangessem os limites inferiores $(0,30 \mathrm{~m}, 0,60 \mathrm{~m}$ e $0,80 \mathrm{~m})$, e acrescentando cerca de $0,50 \mathrm{~m}$ o limite superior para cada intervalo, observando-se os valores de profundidades encontrados nos dados. Daí explica-se a existência de valores não cheios, pois não os mesmos não foram interpolados.

Após o cálculo dos parâmetros " $\mathrm{a}_{0}$ " $\mathrm{e}$ " $\mathrm{a}_{1}$ " esses foram utilizados para o cálculo das profundidades segundo a Equação 2 mostrada na seção 2.5. Como no processamento da RNA as faixa de profundidade foi limitada entre 0,80 a $3,00 \mathrm{~m}$.

\section{RESULTADOS}

Os parâmetros de regressão encontrados foram utilizados para se calcular as profundidades assim como para RNA, depois de treinada, foi realizada a generalização e obteve-se a extração das profundidades nos perfis determinados. A próxima etapa foi o cálculo da diferença entre as profundidades verdadeiras e estimadas, para ambos os métodos, gerando-se gráficos comparativos dos erros encontrados para as profundidades extraídas com os dois métodos e a profundidade medida "in loco" com o ecobatímetro.

Os Gráficos 1 e 2 mostram os resultados da comparação entre as profundidades medidas e as estimadas, ou seja o erro, usando a RNA e o MR, respectivamente. O eixo " $x$ " corresponde à posição do ponto, medida em termos de distância ao longo do perfil, e no eixo " $y$ " a respectiva profundidade.

ENGEVISTA, v. 7, n. 1, p. 73-82, abril 2005
As diferenças entre os valores observados (ecobatímetro) e os modelados mediante a RNA, para estes pontos, são analisadas com o Gráfico 1. Nele, as diferenças entre as profundidades observadas "in loco" e modeladas (RNA) são representadas em função da posição do ponto. Nota-se que esta diferença, em valor absoluto, não ultrapassa, para a maioria dos pontos, $0,50 \mathrm{~m}$ com exceção de dois pontos com erro de $1,67 \mathrm{~m}$ e $0,58 \mathrm{~m}$. Para os demais pontos temos estes valores inferiores ao erro máximo estipulado para levantamentos de Ordem 1, segundo a DHN, que é de $0,50 \mathrm{~m}$. Salienta-se que $99 \%$ do grupo amostral tiveram valores inferiores a $0,50 \mathrm{~m}$.

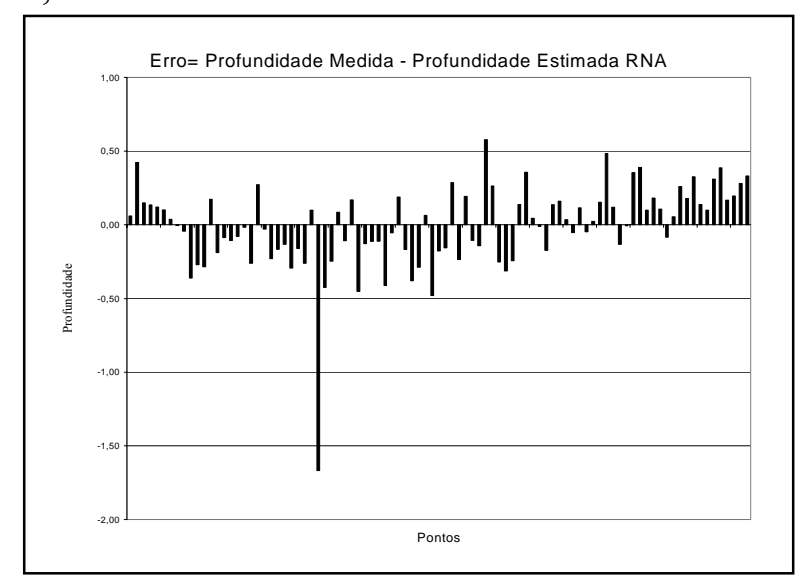

Gráfico 1-Diferença entre as profundidades medidas (no local, isto é, no LB) e estimadas (treinamento e generalização com a RNA) - Erro.

A diferença (erro) calculada entre os valores observados (ecobatímetro) e os modelados por meio do MR são observadas no Gráfico 2. Assim como no Gráfico 10 erro entre as profundidades observadas "in loco" e modeladas com o MR são representadas em função da posição do ponto. Neste caso a maioria das diferenças de profundidade não ultrapassam, em valor absoluto, $0,50 \mathrm{~m}$ com exceção de 7 pontos sendo que neste o maior valor de erro é de $0,71 \mathrm{~m}$. Os demais pontos tem valores inferiores ao erro máximo estipulado para levantamentos de Ordem 1, segundo a 
DHN, que é de 0,50m, como já citado. Conclui-se que $95 \%$ dos valores são inferiores a $0,50 \mathrm{~m}$.

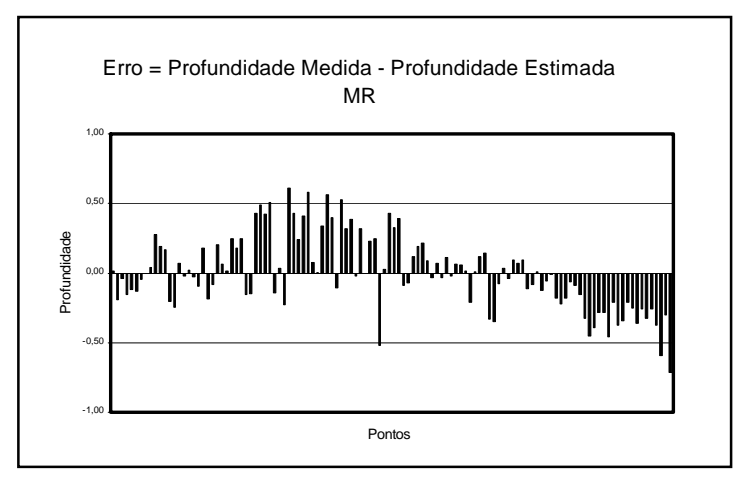

Gráfico 2 - Diferença entre as profundidades medidas (com o LB) e estimadas (Extraídas com o MR) - Erro.

\section{CONCLUSÕES}

O estudo comprovou a viabilidade de estimar profundidades utilizando imagens de satélites de alta resolução espacial com as metodologias de RNA e MR. Os modelos propostos baseiam-se na informação de duas bandas espectrais, a banda 3 (vermelho) e a 2 (verde) do sistema IKONOS II, e a posição $(\mathrm{E}, \mathrm{N})$ do ponto no corpo de água.

A utilização de imagens, de alta resolução espacial, atualmente disponíveis, possibilita a extração de dados de profundidade, cuja dimensão do pixel, isto é , sua resolução espacial está em torno de 0,7-1,0m. Este tipo de estudo é favorecido pelo fato dos sensores de alta resolução operarem principalmente no visível e infravermelho próximo, regiões consideradas mais apropriadas para a estimativa da profundidade de copos de água.

Os resultados obtidos satisfazem as especificações técnicas da DHN, responsável pelos levantamentos batimétricos no Brasil, para LH de Ordem 1 , ou seja, o erro máximo abaixo de $0,50 \mathrm{~m}$. No entanto, verificou-se que as metodologias atendem, apenas, uma faixa restrita de profundidade, entre $0,80 \mathrm{~m}$ a ENGEVISTA, v. 7, n. 1, p. 73-82, abril 2005
$3,00 \mathrm{~m}$, na qual a resposta espectral da coluna de água prevalece sobre o reflexo do fundo e não é fortemente afetada pela absorção.

Tendo em vista o acima exposto e as normas definidas pela DHN conclui-se que, mediante ambas as técnicas as profundidades estimadas podem ser utilizadas na confecção/atualização de cartas náuticas de Ordem 1, em regiões de profundidades de no mínimo $0,80 \mathrm{~m}$ até no máximo $3,0 \mathrm{~m}$. Para as profundidades menores que $0,80 \mathrm{~m}$ a resposta espectral influencia erroneamente o aprendizado da RNA e a modelagem do MR, pois são faixas onde a resposta espectral está fortemente relacionada com turbidez e movimentos da água. Para as profundidades maiores que $3,00 \mathrm{~m}$ a resposta espectral é sempre semelhante, isto é, não existe diferença numérica nos níveis digitais, portanto não acrescentando informações.

Finalmente destaca-se que a RNA obteve um desempenho superior a MR, mas cabe também ressaltar que para as especificações técnicas da DHN, responsável pelos LB as duas metodologias atenderam a precisão.

\section{AGRADECIMENTOS}

Os autores agradecem o apoio e a cooperação do Departamento de Geomática, do Curso de pós-graduação em Ciências Geodésicas da Universidade Federal do Paraná - UFPR.

\section{REFERÊNCIAS BIBLIOGRÁFICAS}

ABDULLAH, K.; MOHD DIMYATA, K.; CRACKNELL, A. P.; VAUGHAN R. A. Evaluation of Landsat TM and Spot data for shallow water bathymetry. 12th Asian Conference on Remote Sensing. 30 Out.Nov. 5. Singapore. 1991. Disponível em http://www.gisdevelopment.net/aars/acrs/.

ABDULLAH, K.; MATJAFRI, M. Z.; DIN, Z. B. Contribution form remote 
sensing in updating bathymetric chart. 21st Asian Conference on Remote Sensing. 4-8 de dezembro. Taipei, 2000.Disponível em http://www.gisdevelopment.net/aars/acrs.

BRASIL. Portaria n. $53 / \mathrm{MB}$, de $1^{\circ}$ de março de 2002. Aprova as "Instruções para controle dos levantamentos hidrográficos pela marinha do Brasil". Disponível em $<$ http://www.dhn.mar.mil.br/chm/Levanta mento/> Acesso em: agosto 2004.

CENTENO, J. A. S. Sensoriamento remoto $e$ processamento de imagens digitais. Editora Curso de Pós Graduação em Ciências Geodésicas. Curitiba, 2004.

DHN - Diretoria de Hidrografia e Navegação. Especificações para levantamentos hidrográficos. Tradução da Publicação Especial da Organização Hidrográfica Internacional. $2^{\mathrm{a}}$ Edição, 1998.

GERMAN, G. W. H.; GAHEGAN, M. N. Neural network architectures for the classification of temporal image sequences. Computers Geosciences, v. 22, n.9, p. 969 - 979, 1996.

HAYKIN, S. Neural networks. A comprehensive foundation. $2 \mathrm{Ed}$. Prentice Hall. New Jersey. p. 842, 1999.

LYZENGA, D. R.. Shallow water bathymetry using combined lidar and passive multispectral scanner data. International Journal of Remote Sensing, 6, 115-125, 1985.

MIGUENS, A. P. Navegação: a ciência e a arte - Navegação Costeira, estimada e em águas restritas. v. 1. Rio de Janeiro: DHN, 2000.

KRUEGER, C. P. Investigações sobre aplicações de alta precisão no âmbito marinho. Tese apresentada ao Curso de Pós Graduação em Ciências Geodésicas do Setor de Tecnologia da Universidade Federal do Paraná, como requisito parcial à obtenção do grau de doutora. Curitiba, 1996.

RIBEIRO, S.R. A.; CENTENO, J. A. S. Clasificación del uso del suelo utilizando redes neurales y el algoritmo MAXVER. Innovación, año 14, n.1, p. 55-60. Antofagasta- Chile, 2002.

RIBEIRO, S.R. A. Integração de imagens Landsat TM e dados auxiliares para a delimitação automática de unidades fisionômicas (paisagem) e geológicas usando redes neurais artificiais. Tese apresentada ao Curso de Pós Graduação em Ciências Geodésicas do Setor de Ciências da Terra da Universidade Federal do Paraná, como requisito parcial à obtenção do grau de doutora. Curitiba, 2003.

SEEBER, G. Satellite geodesy. Foundations, methods and applications. Berlin-New York, 1993.

SPITZER, D.; DIRKS, R.W.J. Bottom influence on the reflectance of the sea. International Journal of Remote Sensing, 8, 279-290, 1987.

TEDESCO, A. Viabilidade do uso de imagens de alta resolução para a atualização de mapas batimétricos. Dissertação de mestrado -Universidade federal do Paraná - Curitiba -PR, 2003.

SWAIN, P. H.; DAVIS, S. M. Remote sensing. The quantitative approach. Editora McGraw-Hill Book Company. United States of America, 1978. 